\title{
ESTEREÓTIPOS DE GÊNERO NO LIVRO DIDÁTICO DE LÍNGUA ESTRANGEIRA
}

As questões de gênero tem sido alvo de grande interesse nos últimos anos, pois tratam das representações de homens e mulheres na sociedade, bem como a forma como estes gêneros interagem nos mais diferentes contextos sociais. Gênero é uma construção social e simbólica, ao passo em que sexo é uma condição biológica. Para Guacira Lopes LOURO (1995, p.174), “a construção de gênero é realizada nas múltiplas instâncias sociais, nas diferentes práticas, espaços e instituições, através das intrincadas redes de relações entre os sujeitos”. Sendo assim, homens e mulheres se constroem na esfera social, submetidos a um condicionamento histórico e cultural que influencia e até mesmo determina suas vivências. Tal idéia se encontra sintetizada por Simone de Beauvoir em sua célebre afirmação: “Não se nasce mulher, torna-se mulher”.

Para Teresa de Lauretis, em seu artigo A tecnologia do gênero, os sujeitos constituem-se no gênero "não apenas pela diferença sexual, e sim por meio de códigos lingüísticos e representações culturais; um sujeito engendrado não só na experiência de relações de sexo, mas também nas de raça e classe” (LAURETIS, apud HOLLANDA, 1994: p.208). Na visão da autora, o gênero é uma representação, e esta representação é a sua construção, que se dá "na academia, na comunidade intelectual, nas práticas artísticas de vanguarda, nas teorias radicais, e até mesmo, de forma bastante marcada, no feminismo” (LAURETIS, apud HOLLANDA, 1994: p.209).

Uma das metas da teoria feminista, de acordo com Jane Flax, “é (e deve ser) analisar as relações de gênero: como estas relações são constituídas e experimentadas e como nós pensamos ou não pensamos sobre elas” (FLAX, 1992: p.219). O estudo das relações de gênero aborda temas como a situação das mulheres e a análise de uma suposta dominação masculina, configurações estas que variam de acordo com a história. Na visão de Flax, o gênero é relacional, isto é: “as relações de gênero são processos complexos e instáveis constituídos por e através de partes inter-relacionadas. Estas partes são interdependentes, ou seja, cada parte não tem significado ou existência sem as outras” (FLAX, 1992: p.228).

As relações de gênero se baseiam em atribuições diferentes e assimétricas para os sexos masculino e feminino. Desta forma, estas relações são sempre relações de poder e 
desigualdade, supostamente controladas por um de seus componentes inter-relacionados: o homem. E, na medida em que o discurso feminista se concentra na mulher, ele considera o homem como um ser livre de configurações de gênero, o que não se sustenta, uma vez que “na perspectiva das relações sociais, homens e mulheres são prisioneiros de gênero, embora de modos altamente diferenciados” (FLAX, 1992: p.229). E dentro deste sistema complexo de relações surgem os estereótipos, "papéis delineados pela sociedade e influenciados por fatores culturais, sociais, econômicos, políticos e étnicos”, constituindo-se na forma mais confortável que os seres humanos lançam mão para "padronizar pessoas, comportamentos, valores e crenças, impondo a outrem identidades que nos ajudam a explicar o mundo" (OLIVEIRA, 2008: p.97).

Partindo destes pressupostos, o objetivo do presente artigo é analisar os estereótipos de gênero que estão presentes no livro didático de língua estrangeira. O material escolhido para esta análise, American Inside Out, é utilizado pelos professores de inglês do Celin (Centro de Línguas e Interculturaidade da Universidade Federal do Paraná), nos níveis Pré Intermediário I e II. Este livro traz uma série de estereótipos que são dignos de análise, e que representam a forma como a sociedade enxerga os homens e as mulheres.

Dentro do contexto do ensino de línguas estrangeiras, é função do livro didático “fornecer subsídios para a construção de posicionamentos críticos que diminuam a letargia daqueles hoje enredados eletronicamente em um ritmo de vida cada vez mais hiperativo e dispersivo” (OLIVEIRA, 2008: p. 92). O livro didático carrega uma série de valores e atitudes disseminadas na sociedade, podendo reforçar ou até mesmo modificar opiniões e padrões de pensamento. Dentro da perspectiva do letramento crítico, nenhuma pedagogia é neutra, e os processos de aprendizagem nunca estão livres de juízo. Sendo assim, os materiais didáticos nunca evitarão as relações de ideologia e poder, colocando-se como "instrumentos a serviço da criação e reprodução de ideologias institucionais e/ou pessoais” (OLIVEIRA, 2008: p.93). Os estereótipos de gênero se encontram enraizados na cultura, e acabam sem dúvida transparecendo nos materiais utilizados em sala de aula, que são como “caixas” de ressonância do que pensa a sociedade. Estes materiais podem e muitas vezes conseguem questionar uma série de valores e criar outros, contribuindo para a solidificação de novas formas de se pensar as relações de gênero. 


\section{Na sala de aula}

Ao longo de dois semestres seguidos, ministrei aulas para duas turmas do Pré Intermediário I utilizando o livro American Inside Out. Irei me concentrar nos capítulos 6 e 9, que trazem os estereótipos de gênero que desejo analisar. Além da análise destes capítulos, comentarei as reações dos alunos a estes estereótipos, trazendo um exemplo concreto de texto produzido em sala, texto este que carrega configurações ideológicas a respeito dos gêneros masculino e feminino.

O tópico da unidade 6 se refere a compras e presentes, vistos como hábitos e atividades predominantemente femininas. Na primeira página da unidade encontramos um texto intitulado What people really want for their birthday, texto este narrado por uma mulher, onde são discutidas as preferências de ambos os gêneros em relação a presentes. Reproduzirei a seguir alguns fragmentos do texto, a fim de identificar as configurações de gênero que nele estão presentes.

The big mistake that women make is that they usually buy clothes. They buy clothes because they like them, and they want other people to wear the clothes they like. "You always wear dark colors, and I want to change you, so I'm going to buy you a brightly colored tie or a pair of Mickey Mouse socks. (p. 34)

Este trecho revela uma série de construções de gênero, especificamente do gênero feminino. Fica evidente o estereótipo da mulher maternal, que tenta impor ao homem o que gosta, e que tenta sempre mudá-lo, infantilizando-o, tratando-o como se fosse seu filho ao mencionar que poderia presenteá-lo com um par de meias do personagem Mickey. No parágrafo seguinte, a autora afirma que isso é um grande erro, já que:

Men usually don't want brightly colored ties or silly socks. The word to remember when you're buying a present for a male is gadgets. Men like anything digital or electronic. (....)

For his last birthday, I gave my husband a small flashlight and a Swiss army knife, the same present that I once gave to a 12-year-old nephew. He was overjoyed. (p. 34)

Visão estereotipada do masculino, ligado ao mundo da tecnologia, mas ainda sim infantilizado, já que a autora admite que deu para seu marido o mesmo presente que havia 
dado ao seu sobrinho de doze anos. Ao indagar meus alunos sobre se os homens gostavam mesmo de aparelhos digitais, a maioria concordou, mas algumas alunas se manifestaram dizendo que também adoravam celulares, aparelhos de MP4, e coisas do gênero. De qualquer forma, no texto temos o estereótipo da mulher maternal, que trata o homem de forma condescendente, sendo infantilizado perante a esposa. A autora ainda afirma que a maioria das mulheres odeia aparelhos eletrônicos, preferindo sempre ganhar jóias, coisa que os homens nunca compreendem, já que sempre dão os tais aparelhos de presente a suas esposas. Assim, podemos perceber que o texto se refere a gostos estereotipados, gostos estes que são próprios de cada gênero, e que refletem os condicionamentos culturais a que homens e mulheres são submetidos.

Na seqüência da unidade, encontramos o tema compras, visto sob as óticas masculina e feminina. Na página 38, há um exercício para preenchimento de lacunas, no qual os alunos devem completar com a palavra Men (homens) ou Women (mulheres). A maioria dos alunos concordou nas seguintes respostas:

a) Men can't stand shopping for clothes.

b) Women don't mind spending hours and hour shopping for clothes.

c) Women spend a lot of time going from store to store, comparing prices and quality.

d) Women / Men don't bother looking at the price tag before they buy.

e) Men don't waste time shopping unless they need something.

f) Men prefer going to the dentist's to going shopping.

O exercício suscitou discussão, já que algumas alunas declararam que não gostavam de fazer compras, e que não gostar disso não era necessariamente uma prerrogativa masculina. Mas a maioria dos alunos homens concordou com as afirmações do exercício, dizendo que fazer compras era uma atividade absolutamente sem graça para eles. Um aluno inclusive contou que foi com sua esposa a uma loja de roupas, e que ela passou mais de uma hora provando várias peças, o que fez com que ele perdesse a paciência e gritasse com ela dentro da loja! O exercício proposto fez com que os alunos refletissem sobre os estereótipos que eles mesmos alimentam, dando a eles chance de concordar ou não com as afirmações. A afirmação $d$, por exemplo, suscitou uma série de polêmicas, pois tanto os alunos quanto as alunas afirmaram dar muita importância ao preço de roupas. O mais interessante foi que os alunos homens “acusaram” as mulheres de não se importar com os valores, e elas por sua vez alegaram que os homens eram desligados, e que também não estavam nem um pouco 
preocupados com esta questão, e por isso optei por deixar as duas alternativas. De qualquer forma, ficaram evidentes na atividade dois estereótipos: o da mulher consumista e preocupada com a aparência, e o do homem prático, pouco preocupado com o que veste, que vai às compras só quando realmente precisa. Estas construções estão enraizadas em nossa sociedade, onde as mulheres usam sua aparência como forma de projeção na esfera social, preocupando-se muito com a própria imagem, ao passo em que os homens estão focados em outros valores que não a imagem e a aparência física.

Ao concluir esta unidade, pedi aos alunos que elaborassem um diálogo entre duas ou mais pessoas dentro do contexto comunicativo que estávamos estudando. Poderia ser entre um comprador e um vendedor, ou entre duas pessoas comprando algo, e assim deixei os alunos livres para fazerem a atividade da forma que quisessem. Como havia apenas três alunos em sala, foi elaborada uma conversa com três pessoas em uma loja. O resultado desta atividade foi muito interessante, e encontra-se reproduzido abaixo:

Woman: Oh baby, this pair of boots is so beautiful!

Man: Do you really need these boots? You bought one last weekend!

Woman: Bou this one is very beautiful and cheap. Let's enter and try on.

Man: Oh my god, here w ego.

Salesperson: Can I help you?

Woman: I want to see that pair of boots.

Salesperson: What's your size? What colors do you prefer?

Woman: My size is 35 and I want to see all colors.

Man: I'll see some TVs. I'll be back soon.

\section{0 minutes later.....}

Man: I don't believe you didn't buy it yet!

Woman: Ok, ok! I'll take the black one and the red one.

Salesperson: Ok, how would you like to pay, sir?

Man: How much are they?

Salesperson: $\$ 600$ dollars.

Man: Oh, I won't pay that!

Woman: Oh, honey, I don't have anything to put on my feet.

Man: Ok, ok! I'll pay it in cash.

Salesperson: Thank you. Here is your receipt.

Os alunos acabaram por reproduzir no texto os estereótipos de gênero discutidos na unidade, de forma irônica e bem-humorada, evidenciando o estereótipo da mulher fútil e consumista, que manipulativamente "gasta o dinheiro do marido" em algo que ele considera 
inútil. Isso mostra como os livros didáticos, tematizando as relações existentes entre os gêneros, dão oportunidade para que os alunos reflitam sobre seus próprios estereótipos e preconceitos, o que pode levar a uma mudança de mentalidade. Não sei se essa mudança ocorreu em minhas aulas, mas achei muito interessante que os alunos tivessem esta chance de debater a existência das relações e dos estereótipos de gênero em nossa sociedade, além de reproduzir em um texto escrito os padrões de comportamento e as crenças que eles mesmos alimentam.

A unidade 9 do livro que utilizamos também traz uma série de estereótipos que merecem atenção. Tais estereótipos estão centrados no feminino, e dão uma pista de como as relações de gênero devem se organizar. Dentro dos estudos de gênero, há uma série de discussões a respeito das diversas formas de representação do feminino na literatura e nas artes em geral. Estas representações são sempre carregadas de ambigüidade, pois concebem a mulher ao mesmo tempo como submissa e angelical, em uma tentativa de valorização do feminino, e como um ser demoníaco, manipulador, que pode causar a ruína do homem, em uma tentativa de depreciar este mesmo feminino. Este estereótipo se materializa, por exemplo, na imagem da "mulher fatal”, imagem esta que povoou o imaginário literário de muitas épocas. De qualquer forma, estas imagens ainda estão fortemente presentes na literatura e no cinema, e também nos livros didáticos, que trazem uma imagem modernizada desta "mulher fatal”. No texto de abertura da unidade 9, temos o resumo de um livro de autoajuda chamado How to Be the Perfect Ms. Right, livro este que traz uma série de regras para se conquistar um homem e manter um relacionamento por bastante tempo. Algumas das regras seguem reproduzidas abaixo:

1. On a first date, you have to be quiet and mysterious.

3. You cannot cut your hair - men prefer it long.

5. You must always hesitate when he asks for a date.

7. You cannot be too honest about your feelings.

8. You must not call him or e-mail him first.

Com estas regras, fica evidente o estereótipo da “mulher fatal” moderna, que usa de uma série de subterfúgios para seduzir o homem, hesitando quando ele a convida para sair, se “fazendo de difícil”, colocando-se como objeto da conquista, e não como sujeito dela. As 
regras são categorias no sentido de que a mulher nunca deve se abrir completamente, sendo sempre um mistério para o homem, que deve tomar a iniciativa da conquista. Além disso, estas regras carregam configurações arcaicas associadas ao “eterno feminino”, tanto em seu aspecto positivo quanto no negativo.

Minhas alunas reagiram fortemente às regras, afirmando que eram machistas e desiguais, e que as mulheres podem tomar a iniciativa da conquista. Percebi que elas nutrem uma forte aversão ao estereótipo de submissão da mulher que as regras parecem veicular. Já os alunos homens concordaram com algumas regras mas discordaram de outras, expressando um temor de que a mulher pudesse querer controlá-los ou manipulá-los. Alguns até afirmaram que gostavam que uma mulher os convidasse para sair, e que não gostariam que ela hesitasse quando fosse convidada para sair. Outros disseram que consideram esse tipo de comportamento infantil e imaturo, pouco condizente com a independência conquistada pela mulher moderna.

Na seqüência da unidade, há um outro exercício, no qual não apresentadas algumas regras sobre como os homens devem se comportar com as mulheres. Algumas seguem reproduzidas abaixo:

a) You must arrive on time for dates - women hate when you keep them waiting.

b) On her birthday, you must not give a woman a gold ring - she'll think you want to marry her, and that's exactly what she wants.

c) You must always pay when you go out. Women want to be equal, but not that equal!

d) You must never talk about other beautiful women, even famous ones.

Para os homens, as regras são claras: nunca se deve dar segurança completa a uma mulher, a não ser no setor financeiro, onde a igualdade nunca será atingida. As regras evidenciam estereótipos ainda muito presentes em nossa sociedade, na qual ainda há uma demanda feminina por um homem que tenha estabilidade financeira, mas que não necessariamente ofereça estabilidade emocional, nunca deixando a mulher ter certeza de seus sentimentos por ela. A afirmação c suscitou forte discussão, e muita polêmica. Alguns alunos homens expressaram desejo de que houvesse igualdade nesse sentido, e que não era justo que só o homem arcasse com as despesas dos programas feitos pelo casal. Algumas alunas disseram que estavam acostumadas a dividir a conta; já outras negaram totalmente a possibilidade de qualquer colaboração, afirmando que o homem sempre deveria pagar. Uma 
aluna, psicóloga que ocupa um cargo importante no setor de Recursos Humanos de uma empresa, confessou que nunca convida seu marido, com quem está há mais de 20 anos, para sair jantar fora. Quando perguntei o porquê dessa atitude, ela afirmou que "quem convida paga”, e que ela nunca havia pagado nada para o marido porque ele deveria ser o homem da relação, e não ela! Os outros alunos discordaram totalmente desta atitude, afirmando que hoje em dia era possível dividir a conta porque as mulheres também trabalham, mas percebi que algumas alunas não se sentem muito confortáveis com esta nova visão de mundo, pois tendem a se sentir exploradas quando tem que arcar com despesas no lugar do homem.

Particularmente, achei de fundamental importância que os alunos tivessem esta oportunidade de refletir sobre as relações de gênero existentes em nossa sociedade. Pude perceber também que os estereótipos apresentados pelo livro estão profundamente enraizados em nossa vida cultural, apesar de todas as modificações que se operaram na vida pósmoderna. Muitas opiniões são influenciadas por um falso feminismo que pretende conferir emancipação à mulher, mas que guarda, em seu inconsciente, concepções muito arcaicas de como uma mulher deve se portar, e de como deve conquistar um homem. Tais opiniões, longe de serem equivocadas, refletem um grande conflito de identidade, conflito este que aflora nas relações de gênero. Homens e mulheres possuem expectativas sobre como cada um deve se comportar, e estas expectativas causam uma série de conflitos nas relações interpessoais. Acho muito interessante que o livro didático de língua estrangeira, dentro da perspectiva do letramento crítico, faça com que os alunos elaborem suas experiências de mundo, comparando opiniões, gerando debates, promovendo discussões que, conforme já dito, podem levar a uma mudança nos padrões de pensamento. Assim, o livro didático, concentrando “capacidades reprodutoras das representações de mundo, funcionando como caixa de ressonância do que pensa a sociedade, ou, mais especificamente, os grupos hegemônicos nela inseridos” (OLIVEIRA, 2008: p.95), acaba tendo, além da prerrogativa de ensinar, uma capacidade transformadora, no sentido de apresentar novas visões de mundo e formar novos pensamentos críticos.

\section{Referências}

BEAUVOIR, Simone de. O segundo sexo. Trad. Sérgio Milliet. Rio de Janeiro: Nova Fronteira, 1980. 
FLAX, Jane. Pós-modernismo e relações de gênero. In: HOLLANDA, Heloísa Buarque de. (org.) Pós-modernismo e política. Rio de Janeiro: Rocco, 1992.

JONES, Vaughan; KAY; Sue; KERR, Philip. American Inside Out Pre-Intermediate. Student’s Book. Oxford: McMillan, 2004.

LAURETIS, Teresa de. A tecnologia do gênero. In: HOLLANDA, Heloísa Buarque de. (org.) Tendências e impasses: o feminismo como crítica da cultura. Rio de Janeiro: Rocco, 1994.

LOURO, Guacira Lopes. Educação e Gênero: a escola e a produção do feminino e do masculino. In: SILVA, Luiz Heron da; AZEVEDO, José Alves de. Reestruturação Curricular. Petrópolis: Vozes, 1995.

OLIVEIRA, Sara. Texto visual, estereótipos de gênero e o livro didático de língua estrangeira. In: Trabalhos de Lingüística Aplicada. Campinas, 2008. 